University of Wollongong

Research Online

Faculty of Engineering and Information

Faculty of Engineering and Information

Sciences - Papers: Part A

Sciences

$1-1-2013$

\title{
Enhanced boron rejection by NF/RO membranes by complexation with polyols: measurement and mechanisms
}

Kha L. Tu

University of Wollongong, Ikt883@uowmail.edu.au

Allan R. Chivas

University of Wollongong, toschi@uow.edu.au

Long D. Nghiem

University of Wollongong, longn@uow.edu.au

Follow this and additional works at: https://ro.uow.edu.au/eispapers

Part of the Engineering Commons, and the Science and Technology Studies Commons

Research Online is the open access institutional repository for the University of Wollongong. For further information contact the UOW Library: research-pubs@uow.edu.au 


\title{
Enhanced boron rejection by NF/RO membranes by complexation with polyols: measurement and mechanisms
}

\author{
Abstract \\ Boron rejection by nanofiltration (NF) and reverse osmosis (RO) membranes in the presence of glycerol, \\ mannitol and sorbitol was investigated as a function of feed solution $\mathrm{pH}$ and boron:polyol molar ratio. In \\ the presence of polyols, significant boron rejection improvement was obtained and the extent of the \\ impact was directly related to the stability constant of the boron-polyol complex. Polyols could complex \\ with boron in either the boric acid or borate anion forms; however the complexation between polyol and \\ boric acid appeared to be incomplete. With and without the presence of polyols, boron rejection was \\ strongly $\mathrm{pH}$ dependent. The increase in boron rejection due to polyol addition was higher for the NF \\ membrane compared to the RO membrane. A boron:polyol molar ratio of 1:1 appeared to be adequate. \\ The presence of polyols did not cause any observable membrane fouling. Results reported here suggest \\ that the addition of polyols could allow NF membranes to be effectively used for boron removal.

\section{Keywords} \\ measurement, polyols, enhanced, boron, mechanisms, complexation, rejection, membranes, ro, nf \\ Disciplines \\ Engineering | Science and Technology Studies

\section{Publication Details} \\ Tu, K. L., Chivas, A. R. \& Nghiem, L. D. (2013). Enhanced boron rejection by NF/RO membranes by \\ complexation with polyols: measurement and mechanisms. Desalination, 310 115-121.
}




\section{Enhanced boron rejection by NF/RO membranes by complexation with polyols: measurement and mechanisms}

Revised Manuscript Submitted to

Desalination

August 2012

Kha L. Tu ${ }^{1}$, Allan R. Chivas ${ }^{2}$, Long D. Nghiem ${ }^{1, *}$

${ }^{1}$ Strategic Water Infrastructure Laboratory and GeoQuEST Research Centre, School of Civil, Mining and Environmental Engineering

University of Wollongong, NSW 2522, Australia

${ }^{2}$ GeoQuEST Research Centre, School of Earth and Environmental Sciences, University of Wollongong, NSW 2522, Australia

* Corresponding author: Long Duc Nghiem, Email: longn@uow.edu.au, Ph +61 242214590 


\begin{abstract}
Boron rejection by nanofiltration (NF) and reverse osmosis (RO) membranes in the presence of glycerol, mannitol and sorbitol was investigated as a function of feed solution $\mathrm{pH}$ and boron:polyol molar ratio. In the presence of polyols, significant boron rejection improvement was obtained and the extent of the impact was directly related to the stability constant of the boron-polyol complex. Polyols could complex with boron in either the boric acid or borate anion forms; however the complexation between polyol and boric acid appeared to be incomplete. With and without the presence of polyols, boron rejection was strongly $\mathrm{pH}$ dependent. The increase in boron rejection due to polyol addition was higher for the NF membrane compared to the RO membrane. A boron:polyol molar ratio of 1:1 appeared to be adequate. The presence of polyols did not cause any observable membrane fouling. Results reported here suggest that the addition of polyols could allow NF membranes to be effectively used for boron removal.
\end{abstract}

Keywords: boron, complexation, polyol, nanofiltration, reverse osmosis, seawater desalination. 


\section{Introduction}

Boron is commonly present in natural waters in the form of boric acid at a wide range of concentrations. The boron abundance in surface water is generally less than $0.5 \mathrm{mgL}^{-1}$, but the level in seawater is significantly higher with an average concentration of approximately 4.6 $\mathrm{mgL}^{-1}$. Concentrations of up to $6.5 \mathrm{mgL}^{-1}$ have been reported in groundwater supplies, but these high concentrations are usually associated with seawater intrusion [1-3]. Although boron is an important nutrient for plants and animals, the range between deficient and toxic levels is very narrow. Some species such as blackberry and citrus are highly susceptible to boron with a tolerance level less than $0.5 \mathrm{mgL}^{-1} \mathrm{~B}$ [4]. Boron is known to be able to damage the reproductive system of animals at sufficiently high concentrations. Current data for boron toxicity to humans was derived from experiments on animals, with a no-observe-adverse-effect-level of $0.22 \mathrm{mg} /(\mathrm{kg}$ bodyweight)/d [5]. In the Guidelines for Drinking Water Quality published in 1993, the World Health Organisation (WHO) recommended a maximum boron level of $0.3 \mathrm{mgL}^{-1}$ in drinking water. In 1998 this value was increased to $0.5 \mathrm{mgL}^{-1}$ mostly because of the limited capability of existing technologies to remove boron [6]. In 2011, the WHO revised the guideline value of boron in drinking water to $2.4 \mathrm{mgL}^{-1}$. This adjustment is due to the lack of reliable toxicity data for boron on human health and the difficulties associated with the removal of boron during water treatment. It is noteworthy that the WHO guideline is exclusively based on human health consideration while for practicality most water authorities also consider aesthetic properties (e.g. visual appearance and odour) and ecological health when setting their drinking water standards. As a result, given the toxicity of boron to plant species as discussed above, almost all seawater desalination plants around the world are still required to target a boron level in the product water of well less than the current WHO guideline value [7].

The removal of boron requires sophisticated technologies [8-9]. Of the many technologies investigated for boron removal to date, ion-exchange (IX) resin and reverse osmosis (RO) were considered to be the two most promising [9]. IX has excellent boron removal capability; however, this technique is associated with the high operating cost of resin regeneration and low compatibility with other processes. On the other hand, RO with its well-known high selectivity and compatibility has attracted much research and was extensively applied for boron removal. Under standard laboratory conditions, boron rejection by seawater RO membranes has been 
reported to be in the range of $88-91 \%$ [10]. This figure could be approximately $10 \%$ lower in full-scale desalination plants because of the higher recovery required by these plants [11-12]. The rejection of boron by nanofiltration (NF) membranes is low and thus their usage for boron removal is not a common practice. Boron rejection by $\mathrm{RO}$ membranes is mostly governed by the membrane used, feed solution $\mathrm{pH}$, operating pressure, temperature, and membrane fouling [7, 13-18].

Although the complexation of boron with polyols has been successfully employed as the basis of selective ion exchange [19-21] and supported liquid membranes [22] for boron removal, this reaction has not been utilised in RO technology to improve boron rejection. In a pioneering work on this topic, Geffen et al. [23] proposed the addition of D-mannitol to the feed solution to increase boron rejection via the complexation between D-mannitol and boric acid. Geffen et al. reported [23] that the reactant's concentration has a strong influence on boron rejection, whereas the reactant's ratio exhibited a slighter effect. Dydo et al. [24] found that N-methylglucamine resulted in a higher boron rejection improvement than using mannitol and sodium D-gluconate. Both studies [23-24] reported a correlation between boron rejection and solution $\mathrm{pH}$. In the former, mannitol was chosen as the model polyol due to its high equilibrium constant [23]. In the latter, N-methylglucamine was selected to represent weakly basic compounds that can be ionised to a significant extent under acidic conditions only [24]. While these two studies demonstrated the potential of using polyols to increase boron rejection by RO and possibly NF membranes, the underlying mechanisms of the interactions between boron, polyol, and the membrane remain poorly understood.

This study aims to investigate the effects of polyols for improving boron rejection by NF/RO membranes. Boron rejection in the presence of polyols was examined as a function of solution $\mathrm{pH}$ and boron:polyol molar ratios. The experimental results were mechanistically explained on the basis of the complexation equilibrium and the properties of boric acid and polyols. Subsequent to the discussion of experimental results, potential applications of the technique are also discussed. 


\section{Materials and Methods}

\subsection{Chemicals and reagents}

Suprapur $\mathrm{HNO}_{3}$ was purchased from Merck Co. (Darmstad, Germany). All other chemicals used were purchased from Sigma-Aldrich (Castle Hill, Australia) at reagent grade. $\mathrm{NaCl}, \mathrm{CaCl}_{2}$, $\mathrm{NaHCO}_{3}$, and $\mathrm{B}(\mathrm{OH})_{3}$ were used to prepare feed solution. $\mathrm{NaOH}$ and $\mathrm{HCl}$ were used for $\mathrm{pH}$ adjustment. Suprapur $\mathrm{HNO}_{3}$ was used for sample dilution and preparation prior to inductivelycoupled plasma mass spectrometry (ICP-MS) analysis. Glycerol, D-mannitol and D-sorbitol were used as model polyols because of their high boron-complexation stability constants (Table 1. These polyols are relatively inexpensive and can be available as food grade chemicals. For simplicity, D-mannitol and D-sorbitol will be referred to as mannitol and sorbitol hereafter. Mannitol and sorbitol are isomers; the only difference is the orientation of the hydroxyl group on carbon 2. The polyols used in this study possess low log $\mathrm{K}_{\mathrm{ow}}$ values which imply a low hydrophobicity (Table 1).

Boron exists in natural waters predominantly in the form of boric acid which behaves as a very weak Lewis acid according to the hydrolysis:

Boric acid is principally present at $\mathrm{pH}$ well below 9.23, whereas at higher $\mathrm{pH}$, borate ions are dominantly present. Boric acid is poorly hydrated and so possesses a small molecular size, whose Stokes radius is estimated to be about $0.155 \mathrm{~nm}$ (which is only double that of the water molecule) [25]. Having three hydroxyl groups, boric acid can form up to six hydrogen bonds with water leading to a strong association with water. 
It is well-known that boric acid and borate ion can react with multiple hydroxyl compounds (polyols) to produce complexes. The complexation, which increases the acidity of boric acid, has been utilised for many years as the basis of boric acid quantitative analysis that cannot be done by direct titration [26]. The complexation of boron with polyols involves two distinct mechanisms: boric acid with polyol (Eq 1 \& Eq 2) and borate ion with polyol (Eq 3 \& Eq 4). Contribution of each mechanism in the overall complexation depends on the solution $\mathrm{pH}$ where boric acid or borate ion is dominantly present.

Stability constants of borate complexes $\left(\mathrm{K}_{3}\right.$ and $\left.\mathrm{K}_{4}\right)$ have been investigated by several studies [27-29], whereas those of boric complexes $\left(K_{1}\right.$ and $\left.K_{2}\right)$ are not available in the literature. The reported $\mathrm{K}_{3}$ of glycerol, mannitol and sorbitol is considerably higher than $\mathrm{K}_{4}$ (Table 1), and the overall complexation yield is in the order glycerol $<$ mannitol $<$ sorbitol. It is noteworthy that $\mathrm{K}_{2}$ and $\mathrm{K}_{4}$ would be promoted when molar concentration of the polyol is in excess of that of boron. 


\section{[TABLE 1]}

\subsection{Cross-flow membrane filtration system}

A nanofiltration membrane (NF90) and a reverse osmosis membrane (ESPA2) were used in this study. Both are thin-film composite membranes whose rejection capacity is accomplished by a thin polyamide layer which is mechanically supported by a porous polysulfone layer. The NF90 membrane (Dow FilmTec, Minneapolis, MN, USA) is a tight NF membrane which is usually used for water softening or brackish water treatment. The ESPA2 membrane (Hydranautics, Oceanside, CA, USA) is a low pressure RO membrane which can be used for the second pass of RO seawater desalination systems. Both membranes were received as flat sheet samples and were stored dry. Detailed properties of the membranes are shown in Table 2.

\section{[TABLE 2]}

A laboratory-scale, cross-flow membrane filtration system which has been described in detail in a previous study [32] was used in this study. The membrane cell was made of stainless steel and had an effective membrane area of $40 \mathrm{~cm}^{2}(4 \mathrm{~cm} \times 10 \mathrm{~cm})$. The channel height of the cell was 2 mm. The unit utilised a Hydra-Cell pump (Wanner Engineering Inc., Minneapolis, MN). Feed pressure and cross-flow velocity were controlled by a bypass valve and a back-pressure regulator. The temperature of the test solution was kept constant using a chiller/heater (S200 AquaCooler, Chester Hill, Australia) equipped with a stainless steel heat exchanger coil, which was submerged in a stainless steel reservoir. Permeate flow was measured by a digital flow meter (Optiflow 1000, Agilent Technologies, Palo Alto, CA) connected to a computer, and the crossflow rate was monitored by a rotameter. Permeate and retentate flows were recycled back to the feed reservoir.

\subsection{Experimental protocol}

Prior to each experiment, the membrane sample was rinsed with milli-Q water to remove any preservative coating layer, then the membrane was compacted using $9 \mathrm{~L}$ milli-Q water at a pressure of approximately $1,000 \mathrm{kPa}$ higher than the normal operating pressure of each membrane. Membrane compaction was conducted for at least $1 \mathrm{~h}$ until a stable baseline flux was obtained. The electrolyte solution, which contains $10 \mathrm{mM} \mathrm{NaCl}, 1 \mathrm{mM} \mathrm{CaCl} 2,1 \mathrm{mM} \mathrm{NaHCO}$, 
predetermined concentration of $\mathrm{B}(\mathrm{OH})_{3}$ and one of the polyols, was then added to the feed reservoir making up to the total feed volume of $10 \mathrm{~L}$. For all experiments, the cross-flow velocity and permeate flux were adjusted to be $42 \mathrm{cms}^{-1}$ and $42 \mathrm{Lm}^{-2} \mathrm{~h}^{-1}$, respectively. The temperature of the feed solution was kept constant at $20 \pm 0.1{ }^{\circ} \mathrm{C}$ during the experiment. The feed solution $\mathrm{pH}$ was raised to 10 by adding $1 \mathrm{M} \mathrm{NaOH}$, and then was incrementally dropped to $\mathrm{pH} 6$ by adding $1 \mathrm{M} \mathrm{HCl}$. The system was operated under a recirculation mode where both permeate and retentate were recirculated to the feed tank. Feed and permeate samples (25 mL each) were collected for analysis once the filtration system had been stabilised for $1 \mathrm{~h}$ at each investigated condition.

Experiments were conducted at two different boron concentrations: $0.43 \mathrm{mM}\left(4.6 \mathrm{mgL}^{-1} \mathrm{~B}\right)$ and $0.093 \mathrm{mM}\left(1 \mathrm{mgL}^{-1} \mathrm{~B}\right)$ in order to verify the results and also the application range of the technique. Boron rejection at $0.43 \mathrm{mM}$ boron was tested with glycerol and mannitol at 1:1 and 1:5 molar ratios, and sorbitol at 1:1, 1:2 and 1:5 molar ratios. Boron rejection at $0.093 \mathrm{mM}$ boron was tested with sorbitol at 1:0.2, 1:1, 1:2 and 1:5 molar ratios. The rejection was calculated from the measured concentrations in the feed $\left(C_{f}\right)$ and permeate $\left(C_{p}\right)$ as: $R(\%)=100 \times\left(1-C_{p} / C_{f}\right)$.

\subsection{Analytical methods}

The concentrations of boron, sodium and calcium were analysed using an Agilent 7500cs ICPMS (Agilent Technologies, Wilmington, DE, USA). A Merck ICP multi-element standard solution was used for calibration. A lithium internal standard (BDH Spectrosol, Poole, U.K.) was spiked online to all standards and samples by an Agilent Internal Standard Tubing Kit. Sample dilution was carried out with 5\% Suprapur nitric acid. To avoid contamination, only plastic apparatus was used for sample preparation and was soaked in 5\% Suprapur nitric acid for at least $24 \mathrm{~h}$ before being used. Calibration was conducted prior to each batch of analysis. The linear regression coefficients $\left(\mathrm{R}^{2}\right)$ for all calibration curves were greater than 0.99 for all elements. Detection limits for ${ }^{11} \mathrm{~B},{ }^{23} \mathrm{Na}$ and ${ }^{44} \mathrm{Ca}$ (expressed as total B, Na and Ca) were approximately 50 $\mathrm{ngL}^{-1}, 140 \mathrm{ngL}^{-1}$ and $1,800 \mathrm{ngL}^{-1}$, respectively. Prior to each batch of analyses, the ICP-MS was tuned by a multi-element tuning solution that contained $1 \mu \mathrm{gL}^{-1}$ of Lithium, Yttrium, Cerium, Thallium and Cobalt. Each analysis was conducted in triplicate and the variation was always less than 5\%. Conductivity and $\mathrm{pH}$ were measured using an Orion 4-Star Plus $\mathrm{pH} /$ conductivity meter (Thermo Scientific, Beverly, MA). The concentration of glycerol, mannitol and sorbitol was determined using a Shimadzu TOC $\mathrm{V}_{\mathrm{CSH}}$ analyser (Shimadzu, Kyoto, Japan). 


\subsection{Qualitative measurement of the boron-polyol complexation constants}

Experiments to qualitatively evaluate the capability of sorbitol, mannitol and glycerol to complex with boric acid were conducted. In the experiments, a $2 \mathrm{M}$ solution of each polyol was allowed to react with $10 \mathrm{mM}$ boric acid in $100 \mathrm{~mL}$ solution. The $\mathrm{pH}$ and conductivity of the reactions were continuously measured. Initial $\mathrm{pH}$ and conductivity of plain boric acid and polyols solution were also recorded. Since the complexation produces a negatively charged complex and a proton (Eq 2), the yield of the boron-polyol complexation is directly proportional to the increase in conductivity or the decrease in $\mathrm{pH}$ of the solution. By comparing the $\mathrm{pH}$ and conductivity of the boric acid solution before and after adding polyols, the stability constant of the complexation $\left(\mathrm{K}_{1} \mathrm{~K}_{2}\right)$ can be qualitatively estimated.

\section{Results and discussion}

\subsection{Boric acid - polyol complexation}

The complexation capability of each polyol with boron appeared in the order sorbitol $>$ mannitol $>$ glycerol (Figure 1). This is also the order of the complexation stability constants at high $\mathrm{pH}$ when boron exists exclusively as borate ion (Table 1). Considerable changes in the conductivity and $\mathrm{pH}$ (Figure 1) imply that negatively charged complexes and protons were produced (Eq 2), and therefore $K_{1} K_{2}$ was significant especially when either sorbitol or mannitol was used as the complexating reagent. The complexation occurred almost spontaneously within the first 5 seconds (data not shown). It is noteworthy that these complexations occurred at $\mathrm{pH}<6$ where boron existed exclusively as boric acid.

\section{[FIGURE 1]}

\subsection{Plain boron and polyol rejection}

The rejections of plain boron and three polyols were found in the order sorbitol $=$ mannitol $>$ glycerol > boron (Figure 2) which is also the order of their molecular weights. Boron rejection was constant at $\mathrm{pH} \leq 8$ and rapidly increased as the solution $\mathrm{pH}$ increased beyond 8 , whereas polyol rejections appeared to be $\mathrm{pH}$ independent. This observation can be attributed to the dissociation of boron and polyols which governs their rejection by charged repulsion mechanism. Possessing $\mathrm{pK}_{\mathrm{a}}$ values greater than 13 (Table 1), the polyols remained in the undissociated form 
in the investigated $\mathrm{pH}$ range and therefore their rejections by the membranes remained constant. On the other hand, the proportion of borate ions increased rapidly as the solution $\mathrm{pH}$ increased beyond the $\mathrm{pK}_{\mathrm{a}}$ value of 9.23 of boric acid and resulted in the substantial increase in boron rejection. The changes in boron rejection as a function of $\mathrm{pH}$ reported here are consistent with previous studies in the literature (e.g. [7, 13]).

\section{[FIGURE 2]}

\subsection{The effects of polyol addition}

\subsubsection{The rejection of typical salts and membrane fouling propensity}

The rejection of $\mathrm{Na}$ and $\mathrm{Ca}$ without the presence of any polyols slightly increased with increasing $\mathrm{pH}$ (Figure 3). This result is consistent with several previous studies (e.g. [32-33]), and could be attributed to the increase in the membrane surface charge at increasing $\mathrm{pH}$. This trend can still be observed in the presence of polyols; however, the rejection of $\mathrm{Na}$ and $\mathrm{Ca}$ was slightly higher than that in the polyol-free condition, especially in the presence of mannitol or sorbitol (Figure 3). This phenomenon can be attributed to the ability of polyols to complex with cations $\mathrm{Na}^{+}$and $\mathrm{Ca}^{2+}$ as previously reported [34].

\section{[FIGURE 3]}

A stable water flux was obtained after five hours of filtration by both membranes regardless of the polyols and their dosage (Figure 4). All three polyols used in this study are hydrophilic (Table 1) and thus their hydrophobic interactions with the membrane surface are expected to be negligible. Although the NF90 membrane showed slightly more permeate fluctuation than the ESPA2 membrane, this fluctuation was less than 2\% (Figure 4) indicating that the addition of polyol to the feed did not lead to significant membrane fouling.

\section{[FIGURE 4]}

\subsubsection{Role of solution $\mathrm{pH}$}

A significant improvement in boron rejection was achieved in the presence of polyols in the feed solution (Figure 5). At the same polyol dose and $\mathrm{pH}$ value, higher increases in boron rejection were obtained generally in the order sorbitol $>$ mannitol $>$ glycerol (Figure 5) which is also the order of the stability constant of the boron-polyol complexes (Section 3.1). The result implies 
that boron-polyol complexes were formed and their rejection is directly related to the stability constant of the complexes.

Boron rejection by the NF90 membrane in the presence of polyol appeared to be more sensitive to $\mathrm{pH}$ and the type of polyols than that by the ESPA2 membrane. The highest improvement in boron rejection by the NF90 membrane (at pH 9 using sorbitol) was 45\%; whereas it was only $20 \%$ by the ESPA2 membrane at the same condition (Figure 5). This is because the ESPA2 membrane has a significantly higher rejection of plain boron than the NF90 membrane. The presence of polyol resulted in a less apparent increase in boron rejection by the ESPA2 compared to the NF90 membrane, particularly at pH 6 and 7 (Figure 5).

Rejection of the boron-polyol complex appeared to be strongly affected by the solution $\mathrm{pH}$. An increase in the solution $\mathrm{pH}$ leads to an increase in boron rejection regardless of the membrane, type of polyols and their dose (Figure 5). This is not solely due to the speciation of boric acid as a function of $\mathrm{pH}$ but also because of the complexation between boron and the polyol. At $\mathrm{pH}$ below the $\mathrm{pK}_{\mathrm{a}}$ value of boric acid of 9.23 , boron exists predominantly as boric acid. According to Eq 2, the complexation between boric acid and polyol can produce protons, and thus lead to a decrease in $\mathrm{pH}$ (Figure 1). As a result, the complexation reaction is more favorable at high $\mathrm{pH}$. In other words, the complexation efficiency increases as the solution $\mathrm{pH}$ increases, leading to a higher boron rejection. It is noted that the complexation between boric acid and polyol was not complete even when the molar concentration of the polyol was five times that of boric acid. Boron rejection in the presence of sorbitol ranged from 45 to 98\% (Figure 5a), whereas the rejection of sorbitol was 98\% (Figure 2a). A similar observation can also be made with mannitol and glycerol. Results reported here indicate that the increase in boron rejection in the presence of polyol depends mostly on the complexation efficiency.

\section{[FIGURE 5]}

Although a high $\mathrm{pH}$ condition was more favourable for the complexation between boron and polyols, the increase in boron rejection due to the addition of polyol to the feed solution was relatively uniform within the $\mathrm{pH}$ range of 6 to 10 investigated here, particularly for the NF90 membrane (Figure 5). For instance, the increase in boron rejection by the NF90 membrane due to sorbitol addition was approximately 35\% throughout the $\mathrm{pH}$ range of 6 and 10 (Figure 5a). A 
possible explanation for this observation is the interplay between the speciation of boric acid and the complexation between boric acid and the polyol as the feed solution $\mathrm{pH}$ increases. At $\mathrm{pH}$ from 6 to 8, boric acid is dominantly present. The rejection of plain boron is low whereas the rejection of boron in the presence of a polyol depends on the efficiency of the complexation reaction. As the solution $\mathrm{pH}$ increases, the complexation efficiency increases; however, the rejection of plain boron also increases because of the speciation of boric acid. As a result, the net increase in boron rejection appears to be constant over the entire $\mathrm{pH}$ range investigated in this study (Figure 5a).

\subsubsection{Role of boron:polyol ratio}

Although the boron:polyol molar ratio could affect the types of complex formed (Section 2.1), there was no discernible difference in boron rejection between sufficient and excess sorbitol concentrations. The boron:sorbitol molar ratio of 1:1, 1:2 and 1:5 showed a similar boron rejection across the whole $\mathrm{pH}$ range (Figure 6). This can be attributed to the high rejection of sorbitol by the NF90 membrane (Figure 2). It is noteworthy that even at a very low sorbitol concentration (i.e. boron:sorbitol molar ratio of 1:0.2), a considerable increase in boron rejection could be observed (Figure 6). Nevertheless, at $\mathrm{pH} 10$, the increase in boron rejection at the boron:sorbitol molar ratio of 1:0.2 was substantially lower than that at the ratio of 1:1. This is because at high $\mathrm{pH}$, the complexation between boron and sorbitol is complete and boron rejection is governed mostly by the molar ratio between boron and sorbitol. Results reported here indicate that a small dosage sorbitol (i.e. in the range of 3.4 to $17 \mathrm{mgL}^{-1}$ corresponding to boron:sorbitol molar ratio of 1:0.2 to 1:1) could be adequate to achieve a significant increase in boron rejection by the NF90 membrane. According to the market overview by ICIS (www.icis.com/chemicals/sorbitol/), the cost of sorbitol in the first quarter of 2012 is from 0.82 $0.91 \mathrm{US} \$ / \mathrm{kg}$. Therefore, the addition of polyols such as sorbitol to feed water to improve the rejection of boron by a NF membrane can be a practical approach for the removal of boron.

\section{[FIGURE 6]}

\section{Conclusions}

The addition of polyols including glycerol, mannitol or sorbitol to the feed can substantially improve boron rejection. The efficiency of each polyol to improve boron rejection was directly 
related to the stability constant of their complexation with boron. Polyols could complex with boron in either the boric acid or borate anion form; however the complexation between polyol and boric acid appeared to be incomplete. The increase in boron rejection due to polyol addition was higher for the NF membrane compared to the RO membrane. A boron:polyol molar ratio of 1:1 appeared to be adequate and a higher concentration of polyol did not lead to any further increase in boron rejection. A considerable improvement in boron rejection was observed even when the boron:sorbitol molar ratio was as low as 1:0.2. The presence of polyols did not cause any observable membrane fouling issue. Results reported here suggest that the addition of polyols could allow NF membranes to be effectively used for boron removal.

\section{References}

1. Parks, J.L. and M. Edwards, Boron in the Environment. Critical Reviews in Environmental Science and Technology, 2005. 35: p. 81-114.

2. Coughlin, J.R., Sources of human exposure: Overview of water supplies as sources of boron. Biological Trace Element Research, 1998. 66: p. 87-100.

3. Argust, P., Distribution of boron in the environment. Biological Trace Element Research, 1998. 66: p. 131-143.

4. Butterwick, L., N.d. Oude, and K. Raymond, Safety assessment of boron in aquatic and terrestrial environments Ecotoxicology and Environmental Safety, 1989. 17: p. 339-371.

5. WHO, Trace Elements in Human Nutrition and Health. 1996, Geneva: World Health Organization.

6. WHO, Guidelines for Drinking Water Quality 4th Edition. 2011, Geneva.

7. Tu, K.L., L.D. Nghiem, and A.R. Chivas, Boron removal by reverse osmosis membranes in seawater desalination applications. Separation and Purification Technology, 2010. 75: p. 87-101.

8. Bick, A. and G. Oron, Post-treatment design of seawater reverse osmosis plants: boron removal technology selection for potable water production and environmental control. Desalination, 2005. 178: p. 233-246.

9. Kabay, N., E. Güler, and M. Bryjak, Boron in seawater and methods for its separation - A review. Desalination, 2010. 261: p. 212-217.

10. Fritzmann, C., J. Löwenberg, T. Wintgens, and T. Melin, State-of-the-art of reverse osmosis desalination. Desalination, 2007. 216: p. 1-76.

11. Greenlee, L.F., D.F. Lawler, B.D. Freeman, B. Marrot, and P. Moulin, Reverse osmosis desalination: Water sources, technology, and today's challenges. Water Research, 2009. 43: p. 2317-2348. 
12. Glueckstern, P. and M. Priel, Optimization of boron removal in old and new SWRO systems. Desalination, 2003. 156: p. 219-228.

13. Hilal, N., G.J. Kim, and C. Somerfield, Boron removal from saline water: A comprehensive review. Desalination, 2011. 273: p. 23-35.

14. Koseoglu, H., N. Kabay, M. Yüksel, S. Sarp, Ö. Arar, and M. Kitis, Boron removal from seawater using high rejection SWRO membranes - impact of $\mathrm{pH}$, feed concentration, pressure, and cross-flow velocity. Desalination, 2008. 227: p. 253-263.

15. Güler, E., N. Kabay, M. Yüksel, E. Yavuz, and Ü. Yüksel, A comparative study for boron removal from seawater by two types of polyamide thin film composite SWRO membranes. Desalination, 2011. 273: p. 81-84.

16. Huertas, E., M. Herzberg, G. Oron, and M. Elimelech, Influence of biofouling on boron removal by nanofiltration and reverse osmosis membranes. Journal of Membrane Science, 2008. 318: p. 264-270.

17. Tu, K.L., A.R. Chivas, and L.D. Nghiem, Effects of membrane fouling and scaling on boron rejection by nanofiltration and reverse osmosis membranes. Desalination, 2011. 279: p. 269-277.

18. Oo, M.H. and S.L. Ong, Boron removal and zeta potential of RO membranes: Impact of pH and salinity. Desalination and Water Treatment, 2012. 39: p. 83-87.

19. Jacob, C., Seawater desalination: Boron removal by ion exchange technology. Desalination, 2007. 205: p. 47-52.

20. Nadav, N., Boron removal from seawater reverse osmosis permeate utilizing selective ion exchange resin. Desalination, 1999. 124: p. 131-135.

21. Simonnot, M.-O., C. Castel, M. NicolaÏ, C. Rosin, M. Sardin, and H. Jauffret, Boron removal from drinking water with a boron selective resin: is the treatment really selective? Water Research, 2000. 34: p. 109-116.

22. Bachelier, N., C. Chappey, D. Langevin, M. Métayer, and J.F. Verchère, Facilitated transport of boric acid by 1,3-diols through supported liquid membranes. Journal of Membrane Science, 1996. 119: p. 285-294.

23. Geffen, N., R. Semiat, M.S. Eisen, Y. Balazs, I. Katz, and C.G. Dosoretz, Boron removal from water by complexation to polyol compounds. Journal of Membrane Science, 2006. 286: p. 45-51.

24. Dydo, P., I. Nemś, and M. Turek, Boron removal and its concentration by reverse osmosis in the presence of polyol compounds. Separation and Purification Technology, 2012. 89: p. 171-180.

25. Park, J.K. and K.J. Lee, Diffusion coefficients for aqueous boric acid. Journal of Chemical \& Engineering Data, 1994. 39: p. 891-894.

26. Belcher, R., G.W. Tully, and G. Svehla, A comparative study of various complexing agents (polyols) used in the titration of boric acid. Analytica Chimica Acta, 1970. 50: p. 261-267. 
27. Van Duin, M., J.A. Peters, A.P.G. Kieboom, and H. Van Bekkum, The pH dependence of the stability of esters of boric acid and borate in aqueous medium as studied by ${ }^{11} \mathrm{~B}$ NMR. Tetrahedron, 1984. 40: p. 2901-2911.

28. Van Duin, M., J.A. Peters, A.P.G. Kieboom, and H. Van Bekkum, Studies on borate esters II1 1 For part I see reference 7. Structure and stability of borate esters of polyhydroxycarboxylates and related polyols in aqueous alkaline media as studied by ${ }^{11} \mathrm{~B}$ NMR. Tetrahedron, 1985. 41: p. 3411-3421.

29. Makke M, Kieboom A. P. G., and Bekkum van H., Studies on borate esters III. Borate esters of D-mannitol, D-glucitol, D-fructose and D-glucose in water. Recueil des Travaux Chimiques des Pays-Bas, 1985. 104: p. 230-235.

30. Power, P.P. and W.G. Woods, The chemistry of boron and its speciation in plants. Plant and Soil, 1997. 193: p. 1-13.

31. Nghiem, L.D., A.I. Schäfer, and M. Elimelech, Removal of natural hormones by nanofiltration membranes: measurement, modeling and mechanisms. Environmental Science and Technology, 2004. 38: p. 1888-1896.

32. Tu, K.L., L.D. Nghiem, and A.R. Chivas, Coupling effects of feed solution $\mathrm{pH}$ and ionic strength on the rejection of boron by NF/RO membranes. Chemical Engineering Journal, 2011. 168: p. 700-706.

33. Childress, A.E. and M. Elimelech, Relating nanofiltration membrane performance to membrane charge (electrokinetic) characteristics. Environmental Science and Technology, 2000. 34: p. 3710-3716.

34. Anoyal, S.J., Complexing of polyols with cations. Tetrahedron, 1974. 30: p. 1695-1702. 
Table 1: Properties of the polyols used in this study [27-30].

\begin{tabular}{|c|c|c|c|c|c|c|c|c|}
\hline \multirow[t]{2}{*}{ Polyol } & \multirow{2}{*}{$\begin{array}{c}\text { Molecular } \\
\text { weight } \\
\left(\mathrm{gmol}^{-1}\right) \\
\end{array}$} & \multirow[t]{2}{*}{$\mathrm{pK}_{\mathrm{a}}$} & \multicolumn{4}{|c|}{$\begin{array}{c}\text { Stability constant } \\
\left(\mathrm{Lmol}^{-1}\right)\end{array}$} & \multirow{2}{*}{$\begin{array}{l}\text { Log } \\
\mathrm{K}_{\mathrm{ow}}\end{array}$} & \multirow[t]{2}{*}{ Molecular structure } \\
\hline & & & $\mathrm{K}_{1}$ & $\mathrm{~K}_{2}$ & $\mathrm{~K}_{3}$ & $\mathrm{~K}_{4}$ & & \\
\hline Glycerol & 92 & 13.68 & na & na & $16-25$ & $2.6-3$ & -1.85 & \\
\hline Mannitol & 182 & 13.14 & na & na & 1,060 & 150 & -3.26 & \\
\hline Sorbitol & 182 & 13.14 & na & na & 6,840 & 80 & -3.26 & \\
\hline
\end{tabular}

na: not available

Table 2: Properties of membranes used in this study.

\begin{tabular}{llllll}
\hline Membrane & $\begin{array}{l}\text { Average pore } \\
\text { diameter }^{\text {a }} \\
(\mathrm{nm})\end{array}$ & $\begin{array}{l}\mathrm{Na}^{+} \\
\text {rejection }^{\mathrm{b}} \\
(\%)\end{array}$ & $\begin{array}{l}\mathrm{Ca}^{2+} \\
\text { rejection }^{\mathrm{b}} \\
(\%)\end{array}$ & $\begin{array}{l}\text { Pure water } \\
\text { permeability } \\
\left(\mathrm{Lm}^{-2} \mathrm{~h}^{-1} \mathrm{bar}^{-1}\right)\end{array}$ & $\begin{array}{r}\text { Contact } \\
\text { angle }\left(^{\circ}\right)\end{array}$ \\
\hline NF90 & 0.68 & 87.2 & 88.6 & 10.5 & 50.9 \\
\hline ESPA2 & na & 98.3 & 99.5 & 4.0 & 43.3 \\
\hline
\end{tabular}

${ }^{\mathrm{a}}$ Ref [31].

${ }^{\mathrm{b}}$ Rejection data were recorded at $\mathrm{pH} 8$.

na: not available. 


\section{FIGURE CAPTIONS}

Figure 1: Changes in $\mathrm{pH}$ and conductivity as a result of complexation between $10 \mathrm{mM}$ boric acid and $2 \mathrm{M}$ glycerol, mannitol or sorbitol.

Figure 2: The rejection of plain boron and polyols by the (a) NF90 and (b) ESPA2 membranes. Feed solution contains $10 \mathrm{mM} \mathrm{NaCl}, 1 \mathrm{mM} \mathrm{CaCl}_{2}, 1 \mathrm{mM} \mathrm{NaHCO}_{3}$, either 0.43 $\mathrm{mM} \mathrm{B}(\mathrm{OH})_{3}$ or $0.43 \mathrm{mM}$ polyol. Feed temperature $20{ }^{\circ} \mathrm{C}$, permeate flux $42 \mathrm{Lm}^{-2} \mathrm{~h}^{-1}$, crossflow velocity $42 \mathrm{cms}^{-1}$. The error bars show the standard deviations of two repetitive experiments.

Figure 3: The rejection of sodium and calcium by the NF90 membrane in polyol-free and polyol-present conditions. The feed solution contains $0.43 \mathrm{mM} \mathrm{B}(\mathrm{OH})_{3}, 2.15 \mathrm{mM}$ polyol (corresponding to a boron:polyol molar ratio of 1:5). Other constituents include $10 \mathrm{mM} \mathrm{NaCl}$, $1 \mathrm{mM} \mathrm{CaCl}_{2}$ and $1 \mathrm{mM} \mathrm{NaHCO}_{3}$, Feed temperature $20{ }^{\circ} \mathrm{C}$, permeate flux $42 \mathrm{Lm}^{-2} \mathrm{~h}^{-1}$ ), crossflow velocity $42 \mathrm{cms}^{-1}$.

Figure 4: Membrane fouling propensity of the NF/RO filtration experiments. Feed solution contains $0.43 \mathrm{mM} \mathrm{B}(\mathrm{OH})_{3}$, either $0.43 \mathrm{mM}$ or $2.15 \mathrm{mM}$ polyol, $10 \mathrm{mM} \mathrm{NaCl}, 1 \mathrm{mM} \mathrm{CaCl} 2$ and $1 \mathrm{mM} \mathrm{NaHCO}$. Feed temperature $20{ }^{\circ} \mathrm{C}$, cross-flow velocity $42 \mathrm{cms}^{-1}$.

Figure 5: Boron rejection by the (a) NF90 and (b) ESPA2 membrane with feed water containing different boron:polyol molar ratios. The feed solution contains $0.43 \mathrm{mM} \mathrm{B}(\mathrm{OH})_{3}$, $10 \mathrm{mM} \mathrm{NaCl}, 1 \mathrm{mM} \mathrm{CaCl}$ and $1 \mathrm{mM} \mathrm{NaHCO}_{3}$. Feed temperature $20{ }^{\circ} \mathrm{C}$, permeate flux 42 $\mathrm{Lm}^{-2} \mathrm{~h}^{-1}$, cross-flow velocity $42 \mathrm{cms}^{-1}$. The error bars show the standard deviations of two repetitive experiments.

Figure 6: Boron rejection by the NF90 membrane with feed water containing different boron:sorbitol molar ratios. The feed solution contains $0.093 \mathrm{mM} \mathrm{B}(\mathrm{OH})_{3}, 10 \mathrm{mM} \mathrm{NaCl}, 1$ $\mathrm{mM} \mathrm{CaCl} 2$ and $1 \mathrm{mM} \mathrm{NaHCO}_{3}$. Feed temperature $20{ }^{\circ} \mathrm{C}$, permeate flux $42 \mathrm{Lm}^{-2} \mathrm{~h}^{-1}$, crossflow velocity $42 \mathrm{cms}^{-1}$. The error bars show the standard deviations of two repetitive experiments. 


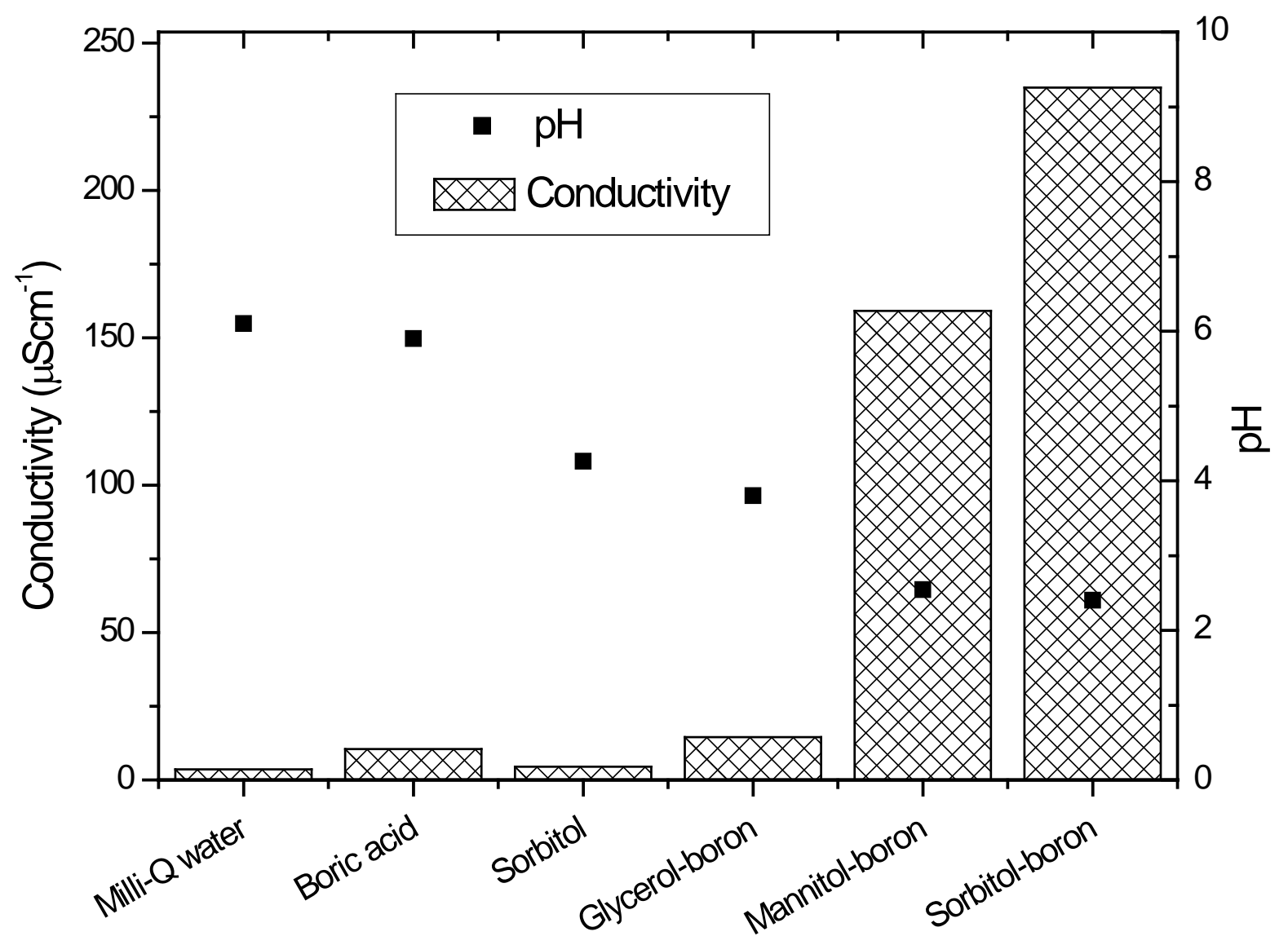

Figure 1 

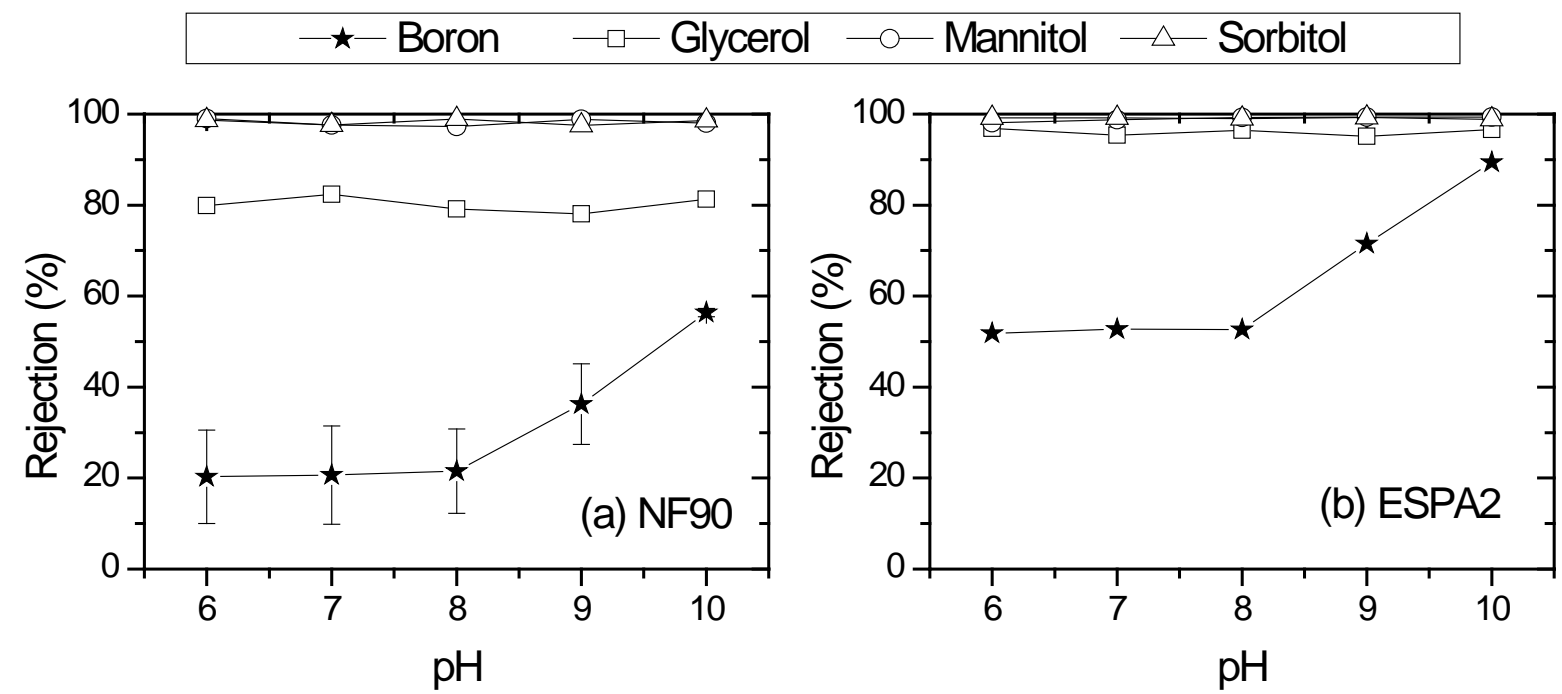

Figure 2 


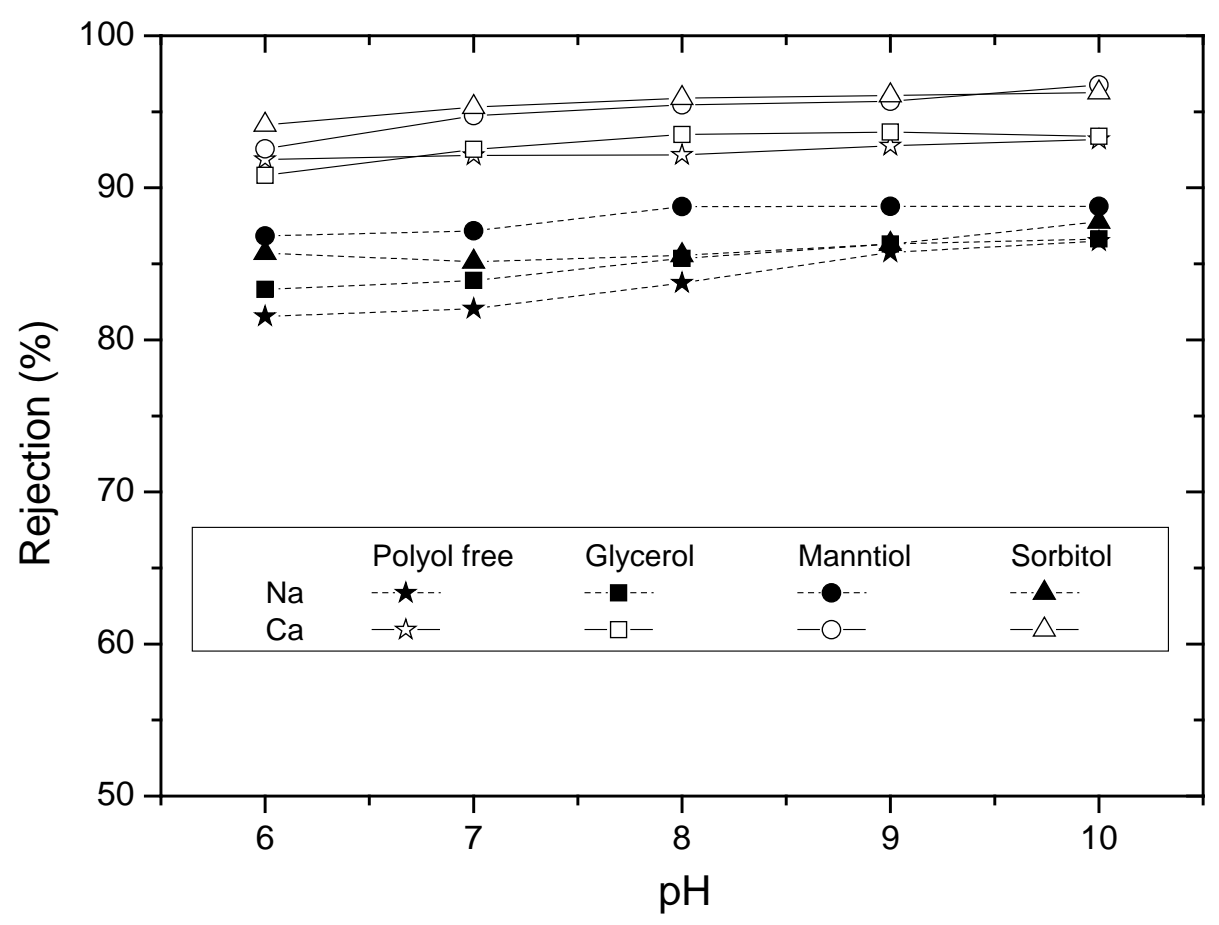

Figure 3 


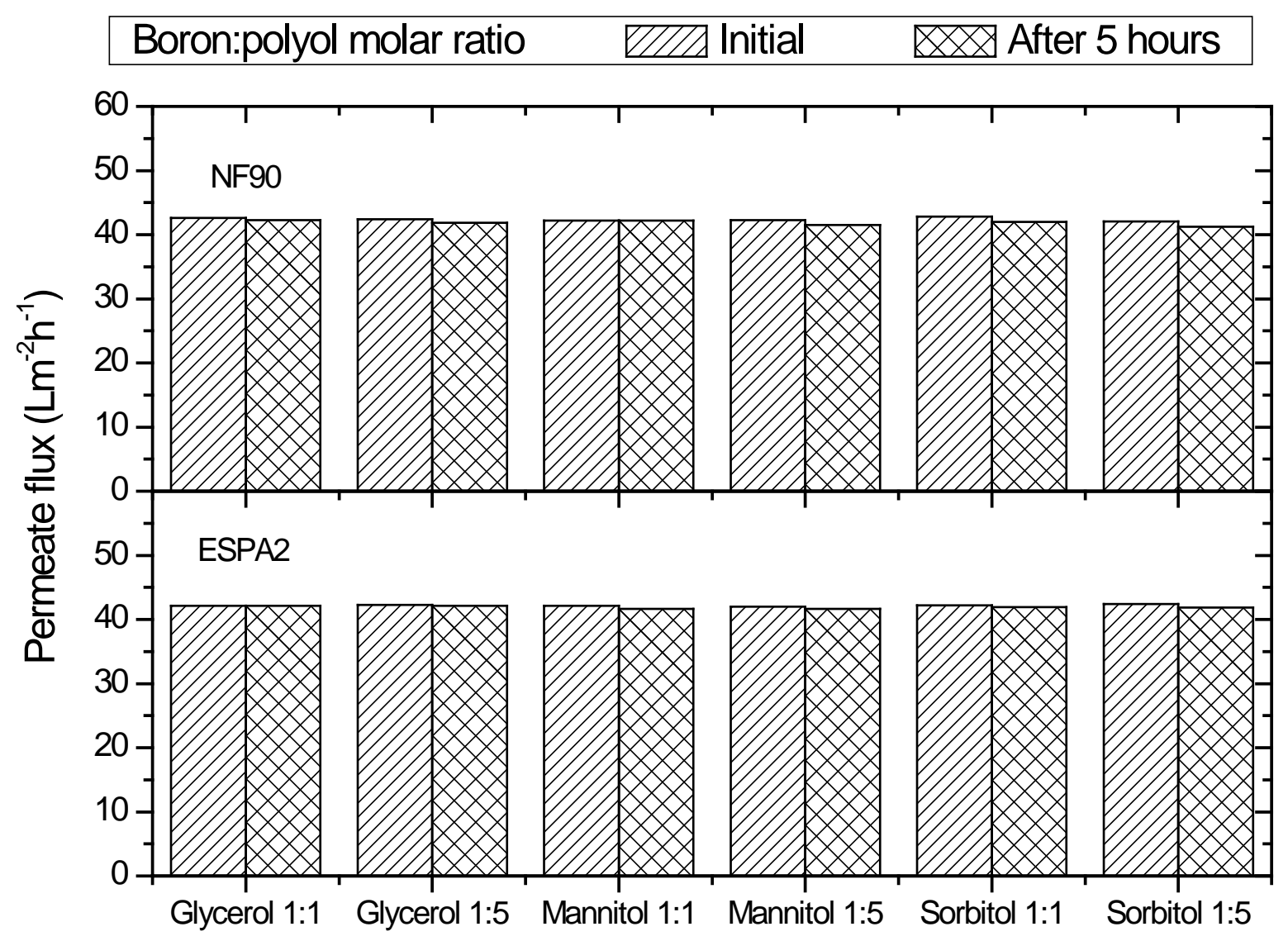

Figure 4 


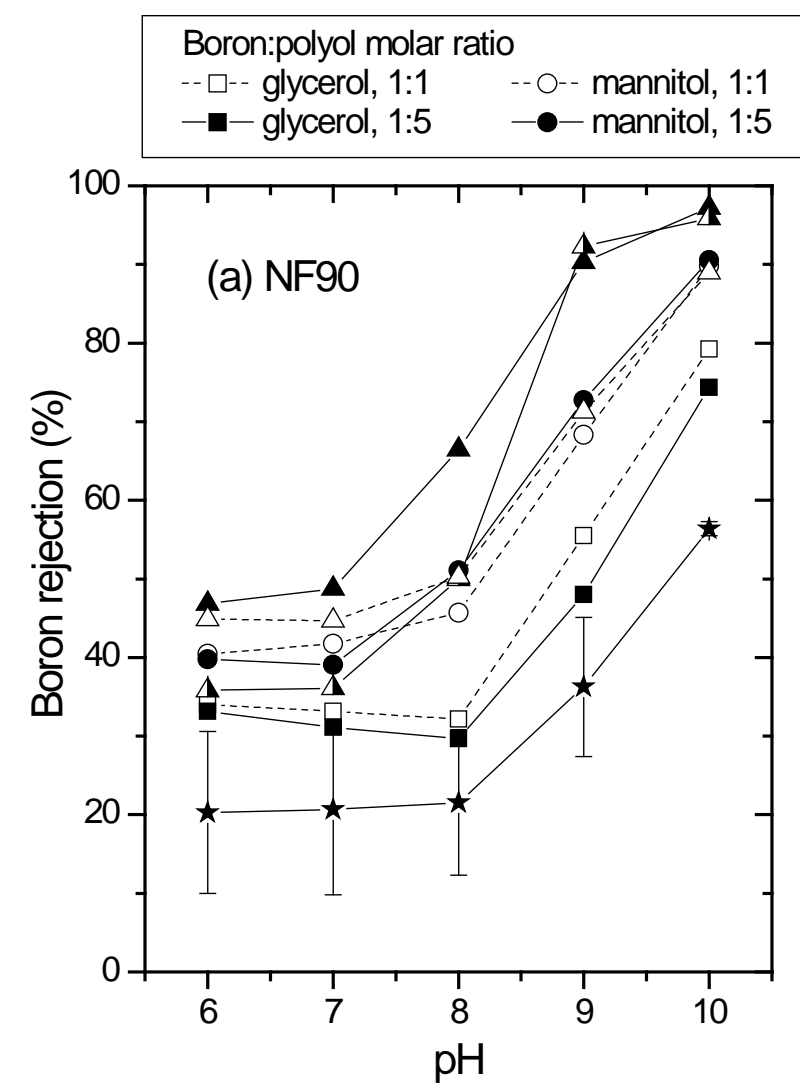

$\begin{array}{ll}--\triangle-\text { sorbitol, 1:1 } & -\boldsymbol{\Delta} \text { - sorbitol, 1:2 } \\ -\boldsymbol{- \Delta} \text { - sorbitol, 1:5 } & -\star-\text { polyol free }\end{array}$

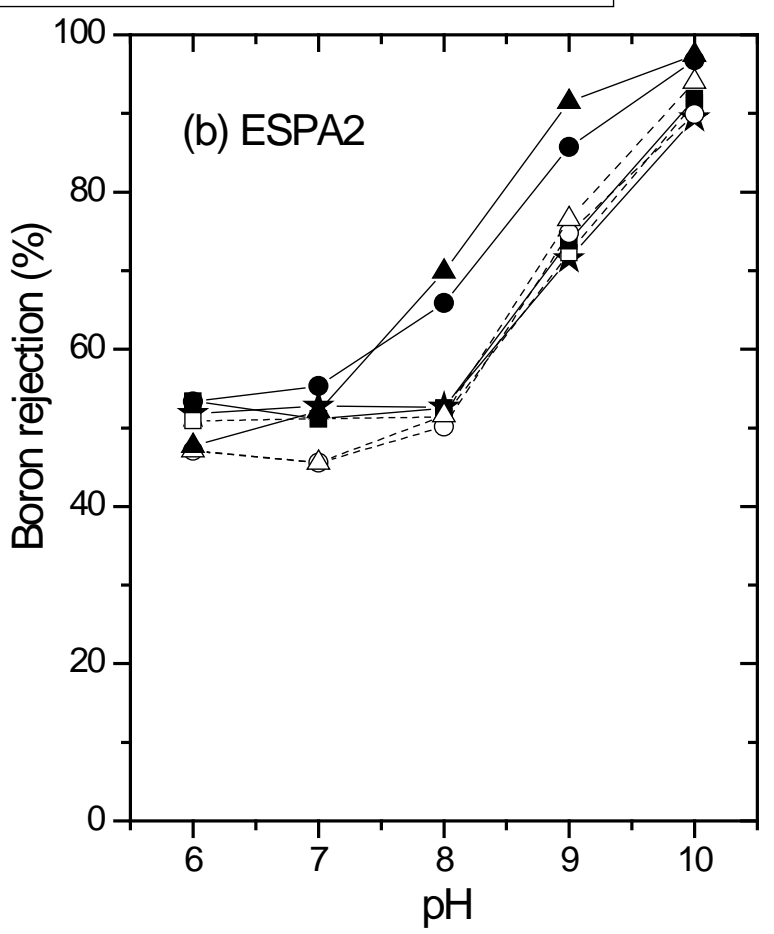

Figure 5 


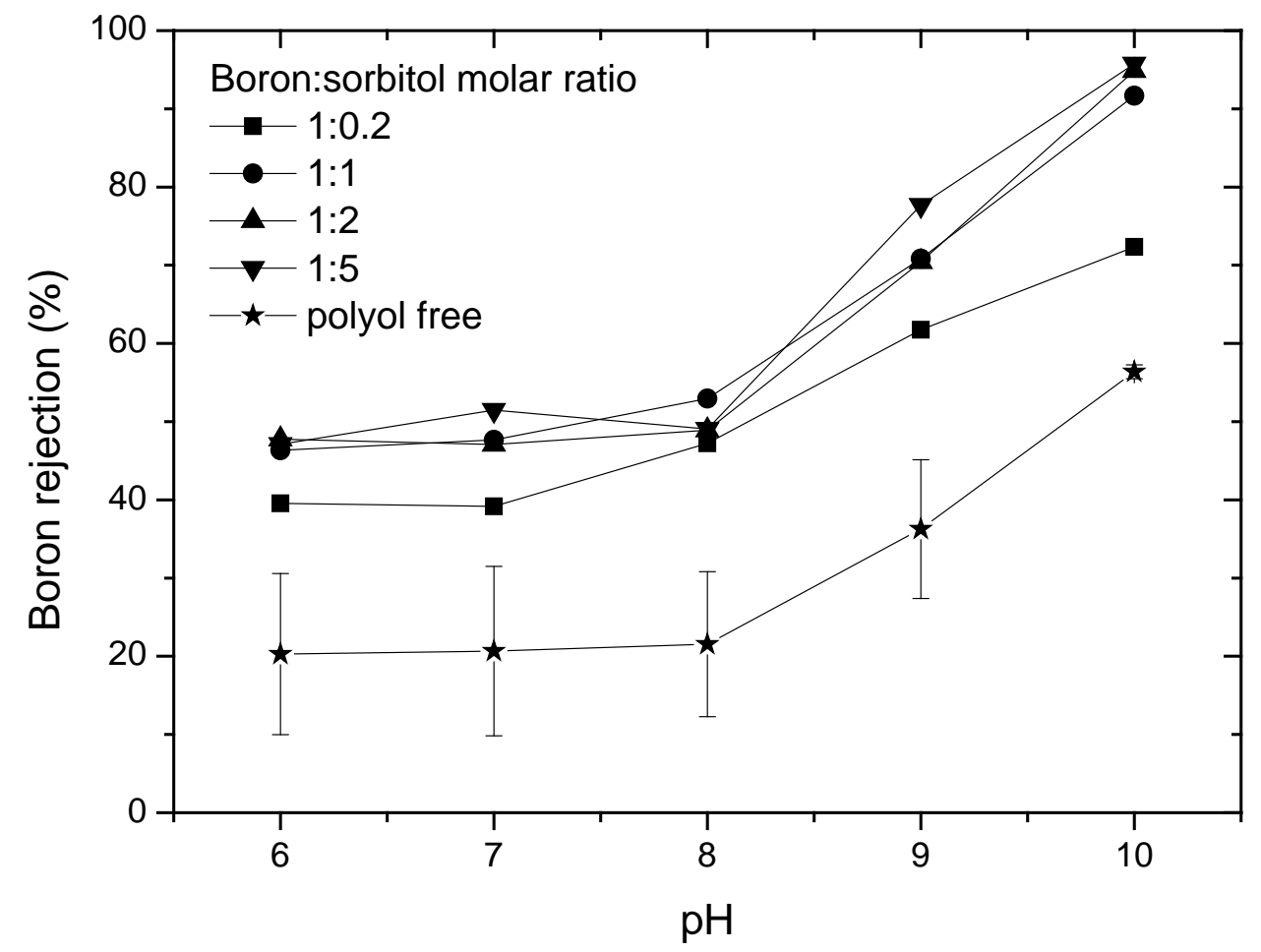

Figure 6 